Pacific Journal of Mathematic 


\section{PROPERTIES OF MARTINGALE-LIKE SEQUENCES}

\section{R. JAMES TOMKINS}

The purpose of this paper is to define a new type of stochastic sequence and to explore its properties. These new sequences of random variables, called eventual martingales, generalize the concept of a martingale.

Several known results concerning the almost sure limiting behavior of martingales are shown to remain valid for eventual martingales. In addition, eventual martingales are compared with three other martingale-like sequences.

Consider a probability space $(\Omega, \mathscr{F}, P)$. A stochastic sequence $\left(X_{n}, \mathscr{F}_{n}, n \geqq 1\right)$ will be called an eventual martingale if and only if (iff)

(1) $P\left[E\left(X_{n} \mid \mathscr{F}_{n-1}\right) \neq X_{n-1}\right.$ infinitely often (i.o.) $]=0$.

This says, in effect, that, except on an event of probability zero, the martingale property $E\left(X_{n} \mid \mathscr{F}_{n-1}\right)=X_{n-1}$ holds for all sufficiently large $n$. In view of the Borel-Cantelli lemma, $\left(X_{n}, \mathscr{F}_{n}, n \geqq 1\right)$ is an eventual martingale if $\sum_{n=1}^{\infty} P\left[E\left(X_{n} \mid \mathscr{F}_{n-1}\right) \neq X_{n-1}\right]<\infty$; in particular, every martingale is an eventual martingale.

In $\S 2$, a decomposition theorem for eventual martingales will be established and used to generalize some known martingale results. Section 3 will explore the relationship among eventual martingales and three other generalizations of martingales.

Assume throughout that $\mathscr{F}_{0}$ is the trivial sigma-field. Let $I(A)$ denote the indicator function of an event $A \in \mathscr{F}$.

2. A decomposition theorem. Crucial to the considerations of this section is the following result.

THEOREM 1. Let $\left(X_{n}, \mathscr{F}_{n}, n \geqq 1\right)$ be an eventual martingale. Then there exist stochastic sequences $\left(M_{n}, \mathscr{F}_{n}, n \geqq 1\right)$ and $\left(Z_{n}, \mathscr{F}_{n}\right.$, $n \geqq 1$ ) such that (i) $X_{n}=M_{n}+Z_{n}$ for all $n \geqq 1$, (ii) $\left(M_{n}, \mathscr{F}_{n}, n \geqq 1\right.$ ) is a martingale, and (iii) $P\left[Z_{n+1} \neq Z_{n}\right.$ i.o. $]=0$.

Proof. Let $d_{1}=X_{1}$ and, for $n \geqq 1$, let $d_{n+1}=X_{n+1}-X_{n}$. If $n \geqq 1$, let $M_{n}=\sum_{k=1}^{n} d_{k} I\left(E\left(d_{k} \mid \mathscr{F}_{k-1}\right)=0\right)$ and $Z_{n}=X_{n}-M_{n}$. Then (i) and (ii) are obvious. Moreover, $Z_{n+1}-Z_{n}=d_{n+1} I\left(E\left(d_{n+1} \mid \mathscr{F}_{n}\right) \neq 0\right)$ so $\left[Z_{n+1} \neq Z_{n}\right] \leqq\left[E\left(d_{n+1} \mid \mathscr{F}_{n}\right) \neq 0\right]$. Hence $0 \leqq P\left[Z_{n+1} \neq Z_{n}\right.$ i.o. $] \leqq$ $P\left[E\left(d_{n+1} \mid \mathscr{F}_{n}\right) \neq 0\right.$ i.o. $]=0$ by $(1)$.

REMARK. Let $B=\left[Z_{n+1} \neq Z_{n}\right.$ i.o. $]$. Theorem 1 (iii) says that, 
except for $\omega \in B$, each (real) sequence $\left\{Z_{n}(\omega)\right\}$ is constant from some point onward. Therefore, $\left\{Z_{n}\right\}$ is an almost surely (a.s.) convergent sequence of random variables (rv). Thus it is evident that $X_{n}$ converges a.s. iff $M_{n}$ converges a.s. Moreover, for any positive real sequence $c_{n} \rightarrow \infty$, the sequences $\left\{X_{n} / c_{n}\right\}$ and $\left\{M_{n} / c_{n}\right\}$ have the same limiting behavior, since $\lim _{n \rightarrow \infty} Z_{n} / c_{n}=0$ a.s.

These facts allow several properties of martingales to remain valid for eventual martingales, as the next theorem shows.

THEOREM 2. Let $\left(X_{n}=\sum_{k=1}^{n} d_{k}, \mathscr{F}_{n}, n \geqq 1\right)$ be an eventual martingale.

(i ) (cf. Chow [4]). If $\sum_{n=1}^{\infty} E\left|d_{n}\right|^{2 r} / n^{1+r}<\infty$ for some $r \geqq 1$, then $\lim _{n \rightarrow \infty} X_{n} / n=0$ a.s.

(ii) (cf. Burkholder [3]). If $E\left(\left(\sum_{n=1}^{\infty} d_{n}^{2}\right)^{1 / 2}\right)<\infty$, then $X_{n}$ converges a.s.

(iii) (cf. Stout [7]). If $\left|d_{n}\right| \leqq M$ a.s. for some $M<\infty$, and if $s_{n}^{2} \equiv \sum_{k=1}^{n} E\left(d_{k}^{2} \mid \mathscr{F}_{k-1}\right) \rightarrow \infty$ a.s., then $\lim \sup _{n \rightarrow \infty} X_{n} /\left(2 s_{n}^{2} \log \log s_{n}^{2}\right)^{1 / 2}=1$ a.s.

Proof. $\left|M_{n}-M_{n-1}\right|=\left|d_{n} I\left(E\left(d_{n} \mid \mathscr{F}_{n-1}\right)=0\right)\right| \leqq\left|d_{n}\right|$. Thus the hypothesis of (i) and the theorem in [4] imply $M_{n} / n \rightarrow 0$ a.s. and, hence, $X_{n} / n \rightarrow 0$ a.s. Furthermore, under (ii), the hypothesis of Theorem 2 of [3] holds for $\left(M_{n}, \mathscr{F}_{n}, n \geqq 1\right)$ so $M_{n}$ converges a.s. which is tantamount to (ii).

Finally, let $v_{n}^{2} \equiv \sum_{k=1}^{n} E\left(d_{k}^{2} I\left(E\left(d_{k} \mid \mathscr{F}_{k-1}\right)=0\right) \mid \mathscr{F}_{k-1}\right)$. Now $0 \leqq$ $P\left[E\left(d_{k}^{2} \mid \mathscr{F}_{k-1}\right) \neq E\left(d_{k}^{2} I\left(E\left(d_{k} \mid \mathscr{F}_{k-1}\right)=0\right) \mid \mathscr{F}_{k-1}\right.\right.$ i.o. $] \leqq P\left[E\left(d_{k} \mid \mathscr{F}_{k-1}\right) \neq\right.$ 0 i.o.] $=0$ by (1) so

(2) $v_{n} / s_{n} \rightarrow 1$ a.s.

But $s_{n} \rightarrow \infty$ a.s. so $v_{n} \rightarrow \infty$ a.s. Hence $\left(M_{n}, \mathscr{F}_{n}, n \geqq 1\right)$ obeys the conditions in Theorem 1 and 2 of [7] so $\lim \sup _{n \rightarrow \infty} M_{n} /\left(2 v_{n}^{2} \log \log v_{n}^{2}\right)^{1 / 2}=1$ a.s. The remark preceding the theorem and (2) now imply (iii).

REMARK. Let $\left(X_{n}=\sum_{k=1}^{n} d_{k}, \mathscr{F}_{n}, n \geqq 1\right)$ be an eventual martingale. Writing

$$
X_{n}=\sum_{k=1}^{n}\left(d_{k}-E\left(d_{k} \mid \mathscr{F}_{n-1}\right)\right)+\sum_{k=1}^{n} E\left(d_{k} \mid \mathscr{F}_{n-1}\right)
$$

yields another decomposition of $X_{n}$ which satisfies (i), (ii) and (iii) of Theorem 1. The next result uses this new decomposition to extend another result of Burkholder [3].

THEOREM 3. Let $\left(X_{n}=\sum_{k=1}^{n} d_{k}, \mathscr{F}_{n}, n \geqq 1\right)$ be an eventual martingale such that $\sup _{n \geqq 1} E\left|X_{n}-\sum_{k=1}^{n} E\left(d_{k} \mid \mathscr{F}_{k-1}\right)\right|<\infty$. For $n \geqq 1$, let $\nu_{n}$ be an $\mathscr{F}_{n-1}$ measurable rv. Then $\sum_{k=1}^{n} \nu_{k} d_{k}$ converges a.s. on the 
event $\left[\sup _{n \geqq 1}\left|\nu_{n}\right|<\infty\right]$. In particular, $X_{n}$ converges a.s. as $n \rightarrow \infty$.

Proof. By hypothesis, $\left(\sum_{k=1}^{n}\left(d_{k}-E\left(d_{k} \mid \mathscr{F}_{k-1}\right)\right)\right.$ is an $\mathscr{L}_{1}$-bounded martingale. So, by Theorem 1 of Burkholder [3],

(3) $\sum_{k=1}^{n} \nu_{k}\left(d_{k}-E\left(d_{k} \mid \mathscr{F}_{k-1}\right)\right)$ converges a.s. on [sup $\operatorname{sul}_{n \geq 1}\left|\nu_{n}\right|<\infty$ ].

Let $C=\left[E\left(d_{n} \mid \mathscr{F}_{n-1}\right) \neq 0\right.$ i.o.]; then $P(C)=0$ by $(1)$. Hence, if $\omega \notin C$, there exists an integer $N=N(\omega)$ such that $E\left(d_{n} \mid \mathscr{F}_{n-1}\right)=0$ for $n \geqq N$. Therefore, $\sum_{k=1}^{n} \nu_{k} E\left(d_{k} \mid \mathscr{F}_{k-1}\right)$ converges a.s. This fact, together with (3), yields the result. Of course, the special case results when $\nu_{n} \equiv 1$ for all $n \geqq 1$.

3. On various generalizations of martingales. Alloin [1] calls $\left(X_{n}, \mathscr{F}_{n}, n \geqq 1\right)$ a progressive martingale iff $\left[E\left(X_{n} \mid \mathscr{F}_{n-1}\right)=X_{n-1}\right] \leqq$ $\left[E\left(X_{n+1} \mid \mathscr{F}_{n}\right)=X_{n}\right]$ for all $n \geqq 1$ and $\lim _{n \rightarrow \infty} P\left[E\left(X_{n} \mid \mathscr{F}_{n-1}\right)=X_{n-1}\right]=$ 1. Mucci [6] calls $\left(X_{n}, \mathscr{F}_{n}, n \geqq 1\right)$ a martingale in the limit iff $\lim _{n \geqq m \rightarrow \infty}\left(E\left(X_{n} \mid \mathscr{F}_{m}\right)-X_{m}\right)=0$ a.s. According to Blake [2], $\left(X_{n}, \mathscr{F}_{n}\right.$, $n \geqq 1)$ is fairer with time iff $\lim _{n \geqq m \rightarrow \infty} P\left[\left|E\left(X_{n} \mid \mathscr{F}_{m}\right)-X_{m}\right|>\varepsilon\right]=0$ for all $\varepsilon>0$.

The final theorem indicates some relationships involving these three concepts and eventual martingales.

THEOREM 4. (i) Every progressive martingale is an eventual martingale.

(ii) Every progressive martingale is a martingale in the limit.

(iii) Every uniformly integrable eventual martingale $\left(X_{n}=\right.$ $\left.\sum_{k=1}^{n} d_{k}, \mathscr{F}_{n}, n \geqq 1\right)$ with $\sup _{n \geqq 1} E\left|\sum_{k=1}^{n} E\left(d_{k} \mid \mathscr{F}_{k-1}\right)\right|<\infty$ is fairer with time.

Proof. If $\left(X_{n}, \mathscr{F}_{n}, n \geqq 1\right)$ is a progressive martingale, then $P\left[E\left(X_{n} \mid \mathscr{F}_{n-1}\right) \neq X_{n-1}\right.$ i.o. $]=\lim _{n \rightarrow \infty} P\left\{\bigcup_{k=n}^{\infty}\left[E\left(X_{k} \mid \mathscr{F}_{k-1}\right) \neq X_{k-1}\right]=\right.$ $\lim _{n \rightarrow \infty} P\left[E\left(X_{n} \mid \mathscr{F}_{n-1}\right) \neq X_{n-1}\right]=0$ so (i) is true.

Let $t=\inf \left\{n \geqq 1: E\left(X_{n} \mid \mathscr{F}_{n-1}\right)=X_{n-1}\right\}$. Since $\left(X_{n}, \mathscr{F}_{n}, n \geqq 1\right)$ is a progressive martingale, $t$ is a stopping rule; i.e. $t \in\{1,2, \cdots, \infty\}$, $P[t<\infty]=1$ and $[t=n] \in \mathscr{F}_{n}$ for all $n \geqq 1$. Now if $t \leqq m$, where $m \geqq 1$, then $E\left(X_{k} \mid \mathscr{F}_{k-1}\right)=X_{k-1}$ for $k \geqq m$. But $[t \leqq m] \in \mathscr{F}_{m}$, so, for

$$
\begin{aligned}
n> & m, \quad\left(E\left(X_{n} \mid \mathscr{F}_{m}\right)-X_{m}\right) I(t \leqq m) \\
= & \sum_{k=m+1}^{n} E\left(I(t \leqq m) E\left(X_{k}-X_{k-1} \mid \mathscr{F}_{k-1}\right) \mid \mathscr{F}_{m}\right)=0 .
\end{aligned}
$$

For each $\omega \in[t<\infty]$, there exists $m_{0}=m_{0}(\omega)$ such that $\omega \in\left[t \leqq m_{0}\right]$ so $E\left(X_{n} \mid \mathscr{F}_{m}\right)-X_{m}=0$ for all $n \geqq m \geqq m_{0}$, proving (ii).

(iii) is a consequence of a result on page 162 of [5], Theorem 3 above and Theorem 1 of Mucci [6]. 
REMARK. None of the statements in Theorem 4 have valid converses. The converses of (i) and (ii) are both shown to be false by letting $d_{1}, d_{2}, \cdots$ be independent $r v$ with $E\left(d_{3}\right)=1, E\left(d_{n}\right)=0$ if $n \neq 3$, defining $X_{n}=\sum_{k=1}^{n} d_{k}$ and taking $\mathscr{F}_{n}$ to be the sigma-field generated by $d_{1}, d_{2}, \cdots, d_{n}$. The converse to (iii) is contradicted by the following example, the first of two examples which show that no general relationship exists between sequence fairer with time and eventual martingales.

EXAMPLE 1. A martingale in the limit need not be an eventual martingale, even if it is uniformly integrable. Let $d_{1}, d_{2}, \cdots$ be independent $r v$ such that $P\left[d_{n}=1\right]=n^{-2}$ whereas $P\left[d_{n}=0\right]=1-n^{-2}$ for $n \geqq 1$. Let $\mathscr{F}_{n}$ be the sigma-field generated by $d_{1}, \cdots, d_{n}$ and set $X_{n}=\sum_{k=1}^{n} d_{k}$. Since $E\left(\sum_{k=1}^{\infty}\left|d_{k}\right|\right)=\sum_{k=1}^{\infty} k^{-2}<\infty$ and $\left|X_{n}\right| \leqq$ $\sum_{k=1}^{\infty}\left|d_{k}\right|$ for all $n \geqq 1,\left\{X_{n}\right\}$ is uniformly integrable. Moreover, $E\left(X_{n} \mid \mathscr{F}_{m}\right)-X_{m}=\sum_{k=m+1}^{n} k^{-2}$ for $n>m \geqq 1$ so $\left(X_{n}, \mathscr{F}_{n}, n-1\right)$ is a martingale in the limit. But $E\left(X_{n} \mid \mathscr{F}_{n-1}\right)=X_{n-1}+n^{-2} \neq X_{n-1}$ for all $n \geqq 2$, so it is not an eventual martingale.

EXAMPLE 2. An eventual martingale need not be fairer with time and, hence, need not be a martingale in the limit. Let $U_{1}, U_{2}$, $\cdots$ be independent $r v$ such that $P\left[U_{n}=-1\right]=2^{-n}$ and $P\left[U_{n}=1\right]=$ $1-2^{-n}$ for $n \geqq 1$. Let $\mathscr{F}_{n}$ be the sigma-field generated by $U_{1}, U_{2}$, $\cdots, U_{n}, d_{1}=U_{1}, d_{n+1}=2^{n} U_{n+1} I\left(U_{n}=-1\right)$ and $X_{n}=\sum_{k=1}^{n} d_{k}$ for $n \geqq 1$. For $k>1$,

$$
\begin{gathered}
E\left(d_{k} \mid \mathscr{F}_{k-1}\right)=2^{k-1} I\left(U_{k-1}=-1\right) E\left(U_{k} \mid \mathscr{F}_{k-1}\right) \\
=\left(2^{k-1}-1\right) I\left(U_{k-1}=-1\right) .
\end{gathered}
$$

Hence $\sum_{k=2}^{\infty} P\left[E\left(X_{n} \mid \mathscr{F}_{n-1}\right) \neq X_{n-1}\right]=\sum_{k=2}^{\infty} P\left[U_{k-1}=-1\right]=\sum_{k=2}^{\infty} 2^{-k+1}<$ $\infty$. Thus $\left(X_{n}, \mathscr{F}_{n}, n \geqq 1\right)$ is an eventual martingale.

But, if $m \geqq 2, E\left(X_{2 m}-X_{m} \mid \mathscr{F}_{m}\right)=\sum_{k=m+1}^{2 m} E\left(E\left(d_{k} \mid \mathscr{F}_{k-1}\right) \mid \mathscr{F}_{m}\right)=$ $\sum_{k=m+2}^{2 m}\left(2^{k-1}-1\right) P\left[U_{k-1}=-1\right]+\left(2^{m}-1\right) I\left(U_{m}=-1\right) \geqq \sum_{k=m+2}^{2 m}(1-$ $\left.2^{-k+1}\right)>\left(1-2^{-2 m+1}\right)>1 / 2$. Hence, if $\varepsilon<1 / 2$,

$$
P\left[\left|E\left(X_{2 m} \mid \mathscr{F}_{m}\right)-X_{m}\right|>\varepsilon\right]=1
$$

for all $m>1$, so $\left(X_{n}, \mathscr{F}_{m}, n \geqq 1\right)$ is not fairer with time.

\section{REFERENCES}

1. C. Alloin, Martingales progressives, Cahiers Centre Études Recherche Opèr., 12 (1970), 201-210.

2. L. H. Blake, A generalization of martingales and two consequent convergence theorems, Pacific J. Math., 35 (1970), 279-283.

3. D. L. Burkholder, Martingale transforms, Ann. Math. Statist., 37 (1966), 1494-1504. 
4. Y. S. Chow, On a strong law of large numbers for martingales, Ann. Math. Statist., 38 (1967), 610.

5. M. Loève, Probability Theory, Van Nostrand (1963).

6. A. G. Mucci, Limits for martingale-like sequences, Pacific J. Math., 48 (1973), 197202.

7. W. F. Stout, A martingale analogue of Kolmogorov's law of the iterated logarithm,

Z. Wahrscheinlichkeitstheorie verw. Geb., 15 (1970), 270-290.

Received January 23, 1975. This research was supported by National Research Council of Canada Grant A7588.

UNIVERSITY OF REGINA 



\section{PACIFIC JOURNAL OF MATHEMATICS}

\section{EDITORS}

RICHARD ARENS (Managing Editor)

University of California

Los Angeles, California 90024

\author{
R. A. Beaumont \\ University of Washington \\ Seattle, Washington 98105
}

\section{J. DugundjI}

Department of Mathematics University of Southern California Los Angeles, California 90007

D. Gilbarg and J. Milgram

Stanford University

Stanford, California 94305

\section{ASSOCIATE EDITORS}
E. F. BECKENBACH
B. H. NeumanN
F. WOLF
K. YoshidA

\section{SUPPORTING INSTITUTIONS}

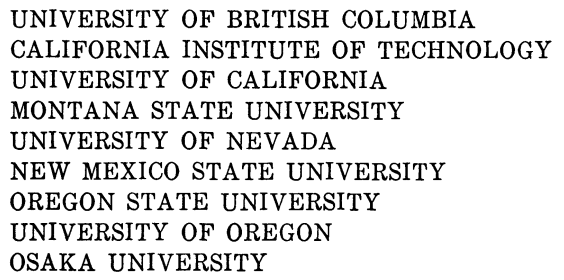

UNIVERSITY OF BRITISH COLUMBIA CALIFORNIA INSTITUTE OF TECHNOLOGY UNIVERSITY OF CALIFORNIA MONTANA STATE UNIVERSITY UNIVERSITY OF NEVADA NEW MEXICO STATE UNIVERSITY OSAKA UNIVERSITY OREGON STATE UNIVERSITY UNIVERSITY OF OREGON

\author{
UNIVERSITY OF SOUTHERN CALIFORNIA \\ STANFORD UNIVERSITY \\ UNIVERSITY OF TOKYO \\ UNIVERSITY OF UTAH \\ WASHINGTON STATE UNIVERSITY \\ UNIVERSITY OF WASHINGTON \\ AMERICAN MATHEMATICAL SOCIETY
}

The Supporting Institutions listed above contribute to the cost of publication of this Journal, but they are not owners or publishers and have no responsibility for its content or policies.

Mathematical papers intended for publication in the Pacific Journal of Mathematics should be in typed form or offset-reproduced, (not dittoed), double spaced with large margins. Please do not use built up fractions in the text of your manuscript. You may however, use them in the displayed equations. Underline Greek letters in red, German in green, and script in blue. The first paragraph or two must be capable of being used separately as a synopsis of the entire paper. Items of the bibliography should not be cited there unless absolutely necessary, in which case they must be identified by author and Journal, rather than by item number. Manuscripts, in triplicate, may be sent to any one of the editors. Please classify according to the scheme of Math. Reviews, Index to Vol. 39. All other communications should be addressed to the managing editor, or Elaine Barth, University of California, Los Angeles, California, 90024.

The Pacific Journal of Mathematics expects the author's institution to pay page charges, and reserves the right to delay publication for nonpayment of charges in case of financial emergency.

100 reprints are provided free for each article, only if page charges have been substantially paid. Additional copies may be obtained at cost in multiples of 50 .

The Pacific Journal of Mathematics is issued monthly as of January 1966. Regular subscription rate: $\$ 72.00$ a year $(6$ Vols., 12 issues). Special rate: $\$ 36.00$ a year to individual members of supporting institutions.

Subscriptions, orders for back numbers, and changes of address should be sent to Pacific Journal of Mathematics, 103 Highland Boulevard, Berkeley, California, 94708.

PUBLISHED BY PACIFIC JOURNAL OF MATHEMATICS, A NON-PROFIT CORPORATION

Printed at Kokusai Bunken Insatsusha (International Academic Printing Co., Ltd.), 8-8, 3-chome, Takadanobaba, Shinjuku-ku, Tokyo 160, Japan. 


\section{Pacific Journal of Mathematics}

\section{Vol. 61, No. 2 December, 1975}

Graham Donald Allen, Francis Joseph Narcowich and James Patrick Williams, An operator version of a theorem of Kolmogorov .......................

Joel Hilary Anderson and Ciprian Foias, Properties which normal operators share with normal derivations and related operators . . . . . . . . . . . . . . . . . . . . .

Constantin Gelu Apostol and Norberto Salinas, Nilpotent approximations and

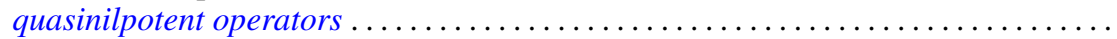

James M. Briggs, Jr., Finitely generated ideals in regular $F$-algebras . . . . . . . . . . .

Frank Benjamin Cannonito and Ronald Wallace Gatterdam, The word problem and power problem in 1-relator groups are primitive recursive ..................

Clifton Earle Corzatt, Permutation polynomials over the rational numbers ...........

L. S. Dube, An inversion of the $S_{2}$ transform for generalized functions . . . . . . . . . . William Richard Emerson, Averaging strongly subadditive set functions in unimodular

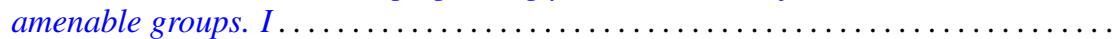

Barry J. Gardner, Semi-simple radical classes of algebras and attainability of

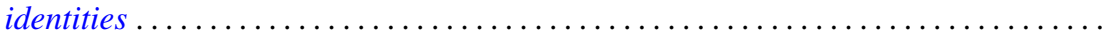

Irving Leonard Glicksberg, Removable discontinuities of A-holomorphic functions ....

Fred Halpern, Transfer theorems for topological structures . . . . . . . . . . . . . . .

H. B. Hamilton, T. E. Nordahl and Takayuki Tamura, Commutative cancellative

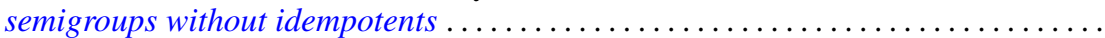

Melvin Hochster, An obstruction to lifting cyclic modules .....................

Alistair H. Lachlan, Theories with a finite number of models in an uncountable power

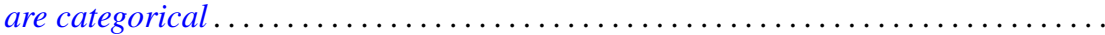

Kjeld Laursen, Continuity of linear maps from $C^{*}$-algebras . . . . . . . . . . . . .

Tsai Sheng Liu, Oscillation of even order differential equations with deviating arguments ....

Jorge Martinez, Doubling chains, singular elements and hyper- $Z$

Mehdi Radjabalipour and Heydar Radjavi, On the geometry of num Thomas I. Seidman, The solution of singular equations, I. Linear equations in Hilbert

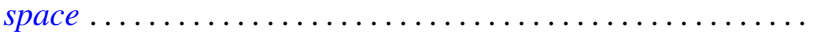

R. James Tomkins, Properties of martingale-like sequences ......

Alfons Van Daele, A Radon Nikodým theorem for weights on von Neumann

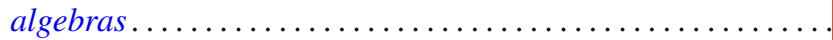

Kenneth S. Williams, On Euler's criterion for quintic nonresidues

Scott Andrew Wolpert, Noncompleteness of the Weil-Petersson metric for Teichmüller

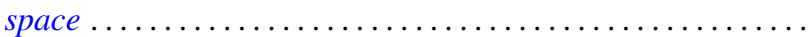

Volker Wrobel, Some generalizations of Schauder's theorem in locally convex

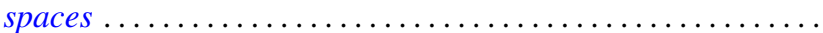

Kelly Denis McKennon, Corrections to: "Multipliers of type $(p, p)$ "; "Multipliers of type $(p, p)$ and multipliers of the group $L_{p}$-algebras"; "Multipliers and the

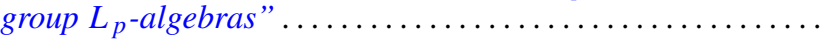

Andrew M. W. Glass, W. Charles (Wilbur) Holland Jr. and Stephen H. McCleary, Correction to: " $a *$-closures to completely distributive lattice-ordered

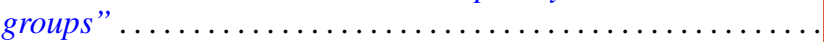

Zvi Arad and George Isaac Glauberman, Correction to: "A characteristic subgroup of

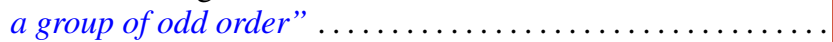

Roger W. Barnard and John Lawson Lewis, Correction to: "Subordination theorems

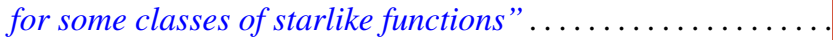

